\title{
El derecho a la desconexión laboral: un derecho emergente en el marco de tecnologías de la información y de la comunicación
}

\author{
The right to disconnect: an emerging right in the context of information \\ and communication technologies
}

Ignacio Camós Victoria* - Alfredo Sierra Herrero**

Resumen: El artículo analiza el reconocimiento de un nuevo derecho en el ámbito de las relaciones laborales: "el derecho a la desconexión laboral". Este derecho se explica porque la conectividad entre las personas por medios digitales se ha extendido en las empresas como una herramienta de trabajo. Tal situación está provocando una vulneración en la limitación de la jornada laboral y, así, del derecho al tiempo libre de los trabajadores. Y es que éstos deben seguir conectados a su función fuera de la jornada, con todas las consecuencias negativas que conlleva para sus vidas, salud y entorno familiar.

Este estudio examina la reciente legislación en Francia -país pionero a este respecto-, y de España, que ha seguido la tendencia de su país vecino. Terminaremos con el caso de Chile, donde por influencia de los ordenamientos citados, existe un proyecto de ley que busca incorporar el derecho en cuestión.

La metodología utilizada es la propia de la dogmática jurídica. Se procedió así a un estudio de las fuentes jurídicas, tanto, ordenamientos legales, jurisprudencia y convenios colectivos, como, asimismo, doctrina chilena y comparada. Los resultados apuntan a efectuar una construcción conceptual de este derecho, determinar los derechos y obligaciones de las partes, y fijar los casos exceptuados. Las conclusiones destacan la importancia de la consagración legal de este derecho, como, a su vez, que éste no sólo contemple la facultad de no contestar, sino que además la prohibición de enviar mensajes fuera de jornada, salvo estrictas excepciones.

Palabras claves: Relaciones laborales; desconexión laboral; jornada de trabajo; tecnologías de la información.

\begin{abstract}
The article analyzes the recognition of a new right in the field of labor relations: "the right to disconnect". This right is explained as the connectivity between people by digital means has spread in enterprises as a work tool. This situation is causing a violation of working hours limitations and, thus, upon workers' right to free time. The case being that workers must remain connected to their jobs outside working hours, with all the negative consequences that this entails for their lives, health and family environment. This study examines recent legislation in France - a pioneer country in this regard- and Spain, which has followed the trend of its neighboring country. We will finish with the case of Chile, where, due to the influence of the aforementioned regulations, there is a legal bill that seeks to enshrine said right into law.
\end{abstract}

\footnotetext{
* Profesor Titular de Derecho del Trabajo y de la Seguridad Social, Universidad de Girona (España), ignacio.camos@udg.edu

*** Profesor Titular de Derecho del Trabajo de la Universidad de los Andes (Chile) asierra@uandes.cl
} 
The methodology used is that of legal science. We studied the legal sources, both statutory, case law and collective agreements, as well as Chilean and comparative doctrine. The results aim to present a conceptual construction of this right, determine the rights and obligations of the parties, and distinguish the cases where it does not apply. The conclusions emphasize the importance of enshrining this right into law, and, also, that it does not only contemplate the right not to answer, but also the prohibition to send messages outside working hours, except for strict exceptions.

Keywords: Labor relations; work disconnection; working day; information technology.

Recibido: 2 abril 2019 Aceptado: 23 junio 2019

\section{Introducción}

El objetivo de este estudio es efectuar un análisis del derecho a la desconexión laboral a raíz del reconocimiento legal del mismo y su entrada en vigor en Francia y España. Igualmente se pretende revisar diferentes ejemplos, a nivel de empresa, donde se están poniendo en práctica medidas tendentes a favorecer la denominada desconexión (digital) laboral o lo que es lo mismo, el derecho a no contestar emails o llamadas telefónicas fuera del horario laboral. Asimismo, examinar un proyecto de ley de Chile sobre la misma materia, donde ciertamente se toma en cuenta la realidad los países mencionados.

La digitalización de las relaciones laborales ha dado lugar, entre sus efectos negativos, a difuminar, si cabe, aún más, la ya de por sí difícil separación entra la vida laboral y familiar. Esto porque se favorece la interconectividad digital, dado el acceso directo a una cantidad de información cada vez mayor. Así se ha intensificado el debate sobre el derecho a no responder llamadas o correos fuera del horario laboral, no en vano, las nuevas formas de estar conectado a través del correo electrónico y/o los teléfonos inteligentes han hecho que el comienzo y el final de la jornada laboral sean, hoy en día, más difusos que nunca.

Se trata de un derecho estrechamente ligado con la regulación legal del tiempo de trabajo y el respeto a los descansos legalmente establecidos. En la mayoría de países la regulación legal de la jornada de trabajo, los descansos y permisos deberían ser suficiente para no entrar en este debate. Y es que, más allá del horario establecido, los trabajadores tienen derecho a desatender los requerimientos vía telefónicas o por e-mail efectuados por la empresa, compañeros y/o clientes, Sin embargo, la realidad es que hoy, más que nunca, se plantea la necesidad de reconocer y/o regular el derecho a la desconexión laboral frente la realidad existente de una prolongación (también en lo virtual) de la jornada de trabajo.

Abierto el debate, tal como trataremos de exponer en este trabajo, las vías para promover este derecho son diversas. Principalmente, contemplarlo como un derecho de los trabajadores que está relacionado con las políticas de mejoras de la conciliación de la vida laboral y familiar, y del ámbito de la salud en el marco de los riesgos psicosociales. Aquí tendría una labor fundamental la negociación colectiva para garantizar este derecho en función de la realidad de cada sector productivo y cada empresa. Cabe apuntar que hay también percepciones en contra de introducir este derecho a la desconexión laboral. En términos generales, se piensa que el restringir a los empleadores que puedan contactar con sus trabajadores, no considera la interconectividad empresarial fruto de la globalización, el potencial de crecimiento empresarial más allá de los mercados de proximidad, y la implementación de trabajos más flexibles. Frente a estos argumentos, sólo cabe sostener que la regulación legal del tiempo de trabajo debe imponerse frente a los abusos o explotación que se traten de imponer, bajo la coartada del crecimiento empresarial y la demanda de los mercados transnacionales. Debe, así, pues, abogarse por una mejor y más 
racional ordenación de la jornada de trabajo, que se adapte a los nuevos tiempos, pero que siempre respete el derecho al descanso de los trabajadores, y permita una efectiva conciliación entre vida profesional y vida privada.

\section{Las tecnologías de la información y de la comunicación en el marco de la actividad laboral}

La búsqueda de la dignidad de las personas es el objetivo central del Derecho del Trabajo1 ${ }^{1}$. Dicha premisa tiene incluso reconocimiento positivo en países, como Chile, donde se establece que "las relaciones laborales deberán fundarse en un trato compatible con la dignidad de la persona" (inc. $2^{\circ}$ art. 2 CdT). Ciertamente, la jornada de trabajo y la remuneración han constituido los ejes de la lucha obrera para alcanzar un nivel de vida digno ${ }^{2}$. De hecho, una de las principales reivindicaciones del mundo obrero fue la de establecer una jornada laboral de ocho horas diarias y de 48 horas semanales, y garantizar un día de descanso que fuera remunerado ${ }^{3}$. De esta forma, tanto la Declaración Universal de Derechos Humanos de 1948 y el Pacto Internacional de Derechos Económicos, Sociales y Culturales consagran como "toda persona tiene derecho al descanso, al disfrute del tiempo libre, a una limitación razonable de la duración del trabajo y a vacaciones periódicas pagadas"4.

La fijación de la limitación de la jornada y el reconocimiento correlativo del derecho a descanso está justificada por razones de diversa índole ${ }^{5}$. Entre ellas, en Europa se destaca su evidente conexión con la seguridad y salud laboral, que es posible observar en la Directiva 2003/88/CEE, de 4 de noviembre de 2003, del Parlamento Europeo y del Consejo, relativa a ciertos aspectos de la ordenación del tiempo de trabajo ${ }^{6}$. A su vez, existen motivos biológicos que residen en la necesidad que tiene toda persona de reponer las energías empleadas en su trabajo ${ }^{7}$. Se habla también consideraciones de orden social y humanitario, pues se considera indispensable que el trabajador pueda disponer de tiempo libre para dedicar a su familia, el estudio y la recreación ${ }^{8}$.

Es así, como la doctrina habla del "derecho al tiempo libre", para emprender labores de diversa índole: conservación personal (descanso, cuidado de salud, deporte, etc.), obligaciones de orden familiar, ocupaciones domésticas, y estudios de carácter profesional. Inclusive que comprenda el ocio contemplativo que permite el desarrollo de la creatividad y la evolución espiritual ${ }^{9}$.

Por estos motivos, la evolución de la jornada ha tendido progresivamente hacia su reducción. Esto se ha logrado, por un lado, por la presión de los trabajadores con miras a obtener un mayor descanso y tiempo para atender de necesidades familiares, sociales, culturales y de ocio; y, por otra parte, el incremento progresivo de la productividad del trabajo humano como consecuencia de los avances tecnológicos aplicados a los procesos productivos ${ }^{10}$.

\footnotetext{
1 Óscar Ermida Uriarte, Meditación sobre el Derecho del Trabajo, Montevideo, Fundación Electra, 2011, 9.

2 Miguel A. Pirolo, “Jornada de trabajo”, Jorge Rodríguez (dir.), Derecho del Trabajo, Buenos Aires, Editorial Astrea, $2010,549$.

${ }^{3}$ Miguel Ángel Chamocho Cantudo, Introducción jurídica a la bistoria de las relaciones de trabajo, Madrid, Dykinson, 2013, 167.

4 Art. 24 Declaración Universal de Derechos Humanos; art. 7 letra d) Pacto Internacional de Derechos Económicos, Sociales y Culturales; véase Irene Rojas Miño, Derecho del Trabajo. Derecho individual del trabajo, Santiago de Chile, Thomson Reuters, 2015, 181.

${ }_{5}^{5}$ Héctor Hugo Barbagelata, Curso sobre la evolución del pensamiento juslaboralista, Montevideo, Fundación de Cultura Universitaria, 2011, 46.

${ }^{6}$ Ignacio García-Perrote Escartín, Manual de Derecho del Derecho, Valencia, Tirant Lo Blanch, 2012, 433.

7 Alejandro Castello, “Jornada de trabajo”, Juan Razo (dir.), Derecho del Trabajo, t. II, 8.

8 Ídem.

9 Véase Sergio Gamonal y Caterina Guidi, Manual del contrato de trabajo, Santiago de Chile, Thomson Reuters, 2015, 197.

10 Antonio Martín, Fermín Rodríguez-Sañudo y Joaquín García, Derecho del Trabajo, Madrid, Tecnos, 2016, 543.
} 
Dentro de estos avances suelen mencionarse los medios electrónicos o virtuales en el trabajo, a través de los cuales se alcanza una mayor autonomía en la organización del tiempo y el espacio, y la posibilidad de conjugar el trabajo y la vida personal ${ }^{11}$.

Es indudable que la introducción de las tecnologías de la información y de la comunicación en el marco de la actividad laboral, ha significado y está significado cambios importantes en el marco de la relación de trabajo. La informática, la telefonía móvil, el correo electrónico, hoy en día son herramientas de trabajo imprescindible para cualquier actividad laboral. Así las cosas, como señala CARDONA "la utilización del correo electrónico, el acceso a internet, la utilización sindical de intranet, la aceptación de la firma electrónica como modo de contraer obligaciones contractuales y de finalizarlas (la dimisión electrónica), el tratamiento automatizado de datos e informaciones relativas al trabajador, la aplicación de las nuevas tecnologías en la vigilancia y control de la prestación laboral, el teletrabajo, son algunas de las manifestaciones de la generalización de las nuevas tecnologías en la empresa"12.

Con todo, este tipo de mejoría se pone en entredicho, básicamente por dos motivos: primero, se produce una prolongación de las horas de trabajo más allá del estándar aplicado a los trabajadores que lo hacen dentro de la empresa; segundo, aunque pareciera que el control empresarial sobre esta clase de trabajo aparece ciertamente atenuado, la realidad indica lo contrario, es decir, este control aumenta, pues toda tarea on-line queda registrada en alguna parte y puede monitorizarse ${ }^{13}$.

De esta manera, se advierte que las nuevas tecnologías están provocando que se desdibuje, y en ocasiones casi desaparezca, la línea divisoria entre la vida personal y laboral del trabajador ${ }^{14}$. Sin duda alguna, en la era digital es más difícil desconectarse del trabajo, no en vano recibimos e-mail a cualquier hora, tenemos acceso al correo electrónico a través del móvil o de sistemas de conectividad online. Estamos expuestos a la hiperconectividad, que implica estar conectado en cualquier lugar y en cualquier momento, a individuos o a redes, en especial a partir de la proliferación de los teléfonos inteligentes o smartphones.

Este panorama presenta el componente negativo de que sea difícil no estar pendiente del trabajo durante los descansos diarios, semanales, días feriados y vacaciones anuales. Ello puede ir en detrimento de los derechos de los trabajadores, que verán poblarse su tiempo de descanso de compromisos laborales y obligaciones derivadas del contrato de trabajo ${ }^{15}$. Todo lo cual termina repercutiendo en la salud física y mental de quienes se encuentra en esta situación.

Vodafone España presentó el año 2016 el estudio “La Flexibilidad Laboral: ¿amiga o enemiga?", uno de los mayores estudios globales acerca de la flexibilidad laboral realizado entre 8.000 empleadores y empleados a lo largo de 10 países en tres continentes. El informe se basa en testimonios de las respuestas de pequeñas y medianas empresas, organizaciones del sector público y multinacionales ${ }^{16}$.

Según este estudio, el $75 \%$ de las empresas en todo el mundo ya cuenta con unas políticas de trabajo flexible que permiten a los empleados modificar su horario y utilizar las últimas tecnologías para

\footnotetext{
11 María Luz Rodríguez Fernández, "Plataformas, microworkersy otros retos del trabajo en la era digital", Oficina de la Organización Internacional del Trabajo para España, Futuro del Trabajo. Trabajo decente para todos, 2017, 10 (disponible en línea: https://www.ilo.org/madrid/fow/trabajo-decente-para-todos/WCMS 548596/lang--es/index.htm)

12 María Belén Cardona Rubert, "Las Relaciones Laborales y el uso de las tecnologías Informáticas", Lan harremanak: Revista de relaciones laborales, Núm. Extraordinario 1, 2003, 157.

13 Rodríguez Fernández, op. cit., 12.

14 Raquel Aguilera y Rosario Cristóbal, "Nuevas tecnologías y tiempo de trabajo: el derecho a la desconexión tecnológica”, El futuro del trabajo que queremos. Conferencia Nacional Tripartita, 28 de marzo de 2017, Iniciativa del Centenario de la OIT (1919-2019), 2017, vol. 2, 333 .

15 Nora María Martínez Yáñez, El régimen jurídico de la disponibilidad horaria, Pamplona, Thomson Reuters, 2011, 29.

16 El estudio "La Flexibilidad Laboral: ¿amigo o enemigo?" fue llevado a cabo por MorarResearch para Vodafone entre septiembre y octubre de 2015. Se entrevistaron digitalmente a un total de 8.000 empleadores y empleados a lo largo de 10 países. Los países participantes fueron: Islandia, Alemania, Hong Kong, Italia, Países Bajos, Singapur, Sudáfrica, España, Reino Unido y Estados Unidos. Véase www.vodafone.com/WorkFlexi y nota de prensa de Vodafone en: https://www.vodafone.es/static/fichero/pro ucm mgmt 651916.pdf
} 
trabajar desde casa o durante sus desplazamientos. En España el porcentaje de empresas que aseguran contar con una política de flexibilidad laboral es del $81 \%$.

Tal y como se apunta en este estudio, el $71 \%$ de los empleados españoles entrevistados utiliza su propio smartphone para trabajar de forma flexible fuera de su lugar de trabajo (frente al 50\% de media del estudio) y sólo el $20 \%$ usa uno proporcionado por la empresa en la que trabaja (frente 14\% de la media).

Por su parte, la Comunidad Laboral Trabajando.com - Universia ha llevado a cabo una encuesta entre más de 1.700 personas para conocer en qué medida las nuevas tecnologías repercuten en la forma en la que los españoles desconectan (o no) de sus responsabilidades profesionales durante el periodo vacacional. Del total de encuestados, el 39\% afirma que sí desconecta durante sus vacaciones, siendo un $31 \%$ los que confirman que no, y el 30\% restante que comenta hacerlo "a medias". ¿Qué factores influyen por tanto en la falta de desconexión? Según los resultados, el 50\% de los participantes apunta como principal motivo su alta responsabilidad profesional, el $42 \%$ confiesa cierto grado de adicción al trabajo, y el $8 \%$ asegura no sentir confianza en la persona que le sustituye ${ }^{17}$.

En síntesis, la implementación de las nuevas tecnologías en el marco de la relación laboral está provocando un importante desajuste entre la vida personal y la vida profesional, trastocando los límites entre una y otra y favoreciendo una mezcla de ambas en beneficio de la vida profesional que se extiende más allá de los límites ordinarios y extraordinarios de duración de la misma. No es un fenómeno nuevo pero la proliferación de nuevos instrumentos digitales ha acentuado este fenómeno haciendo muy difícil, en especial para los trabajadores con responsabilidades, desconectarse del trabajo al finalizar la jornada y no atender llamadas y/o responder e-mails recibidos en su domicilio.

\section{La regulación de la desconexión laboral en Francia}

\subsection{Antecedentes}

Previamente a la regulación del derecho a desconexión existían ejemplos de su reconocimiento en la jurisprudencia y en el marco de los convenios colectivos. La Corte de Casación francesa ya había, aunque con carácter original, revocado un despido de un trabajador responsable de una ambulancia al negarse a responder a las tres llamadas telefónicas realizadas por su empleador en su teléfono móvil personal el 6 de noviembre de 1998 entre las 12.30 p.m. y la 1 pm. Este comportamiento fue considerado falta grave y, en consecuencia, el trabajador despedido. La Corte de casación entendió que no se puede culpar al trabajador por no haber contestado su teléfono fuera de su horario de trabajo, y, por tanto, determinó que no resultaba procedente dicho despido disciplinario.

Por su parte, el acuerdo nacional interprofesional (ANI) del 19 de junio de 2013 sobre la calidad de vida en el trabajo (Accord national interprofessionnel Qualité de vie au Travail), ya había propuesto implementar acciones de formación sobre el uso correcto de las tecnologías de información y comunicación.

En concreto en su art. 17 bajo la rúbrica de: Promouvoir une gestion intelligente des technologies de l'information et de la communication au service de la compétitivité des entreprises, respectueuse de la vie privée des salariés, se reconocía que si bien las tecnologías de la información y la comunicación (uso de correo electrónico, ordenadores portátiles, teléfonos móviles y teléfonos inteligentes; en adelante "TIC") se están convirtiendo cada vez más en una parte integral del entorno de trabajo y son esenciales para el funcionamiento del negocio, deben verse como una herramienta para facilitar el trabajo de los empleados. Sin embargo, las TIC pueden difuminar la línea entre el lugar de trabajo y el hogar, por un lado, entre el tiempo de trabajo y el tiempo dedicado a la vida personal, por el otro.

17 Véase resumen de la encuesta y resumen infográficos en: https://www.trabajando.es/contenido/noticia/1503398420/Soloel-39--de-los-trabajadores-esconecta-durante-las-vacaciones.html 
Se sugería así, en este acuerdo, que las empresas tomen en cuenta este aspecto, identificando las ventajas y desventajas de estos medios digitales. De esta forma, las empresas deberían centrarse en proporcionar capacitación en gestión del cambio y el uso de las TIC para los empleados con dificultades particulares para controlarlos y, tendrían, después de haber consultado a los trabajadores sobre el uso de las TIC en la empresa, adoptar los medios necesarios para conciliar vida personal y vida profesional. Para esto correspondería considerar las características de la empresa y las funciones desempeñadas por los trabajadores, y promover, por ejemplo, la figura del tiempo de desconexión.

A su vez, con posterioridad al Acuerdo nacional interprofesional de 2013, en septiembre de 2015, el informe "Transformación y trabajo de vida digital" elaborado por M. Mettling, Bruno a la atención de la Ministra de Trabajo, Empleo, de Formación profesional y de Diálogo Social abordó el tema de la desconexión laboral. Tal y como se establece en este estudio, en algunas empresas, el vínculo entre la vida privada y profesional se fija tácitamente, se acepta la porosidad y se encuentra el equilibrio en un vínculo muy fuerte con los días de reducción de tiempo de trabajo; en otras empresas, la articulación se ha formalizado en un tipo de acuerdo de "derecho a la desconexión", cuya responsabilidad a menudo afecta al empleado, constatando que la influencia para negociar el derecho a desconectarse depende de muchos factores individuales. Por lo tanto, es importante convertirlo en un problema colectivo, respaldado por la empresa.

Las soluciones mínimas, como la introducción de cartas de usuario para herramientas digitales en las empresas, rara vez se utilizan, excepto en el caso de un litigio. Pero son un buen vector pedagógico: por ejemplo, los correos electrónicos, pueden regular los flujos excesivos al mostrar que cada empleado es ciertamente una víctima, pero también responsable, concluyéndose, entre otros aspectos que "el derecho a la desconexión es, por lo tanto, corresponsabilidad tanto del empleado como del empleador, lo que también implica un deber de desconexión".

Tal y como se apunta en este estudio, algunas empresas han tomado medidas más formales como por ejemplo el establecimiento del principio de un derecho a la desconexión al permitir que los empleados no respondan a las solicitudes efectuadas por sus superiores (por ejemplo, La Poste, APEC, Syntec); o experimentos con los módulos de desconexión de la aplicación (p. Ej. Orange O'zone).

En el Caso de Banque Populaire, en el Capítulo III del Acuerdo de 6 de julio de 2016 sobre las condiciones de vida en el trabajo, titulado: "Entorno de trabajo y conciliación de la vida profesional y privada", se ha incluido un apartado referido al buen uso de correos electrónicos y herramientas remotas donde se ha incluido unas reglas de buenas prácticas para el uso de los mensajes y herramientas remotas vinculadas al derecho individual a desconectar.

No sólo se reconocía el derecho individual a la desconexión para todos, lo que se refleja, en particular, en la ausencia de la obligación del destinatario de responder correos electrónicos fuera de su horario de trabajo y la posibilidad (recomendación) de incluir una mención automática en la firma electrónica del correo especificando esta cuestión. Tal y como hemos apuntado anteriormente, estaba previsto implementar prácticas tendentes a favorecer un buen uso de e-mails, por ejemplo, evitando enviar correos fuera del horario de trabajo, o pregunta cuál es el momento más apropiado para enviar un correo electrónico a fin de no crear un sentido de urgencia innecesario y utilizar las funciones de envío diferido. Se contempla igualmente la puesta en marcha de acciones de sensibilización y formación al respecto.

\subsection{La Ley E1 Khomri}

El contexto antes descrito fue la antesala a la decisión del legislador francés de reconocer este derecho. A partir del $1^{\circ}$ de enero de 2017, el derecho a la desconexión laboral se ha convertido en un derecho en Francia, en aquellas empresas con más de 50 trabajadores. En efecto, fue el primer país en regular la desconexión laboral en la conocida como "ley El Khomr", por el apellido de la ministra de Trabajo (Myriam El Khomri) que promovió la reforma laboral en la que se incluía este derecho. La Ley 
en realidad tiene la denominación de LOI n 2016-1088 du 8 août 2016 relative au travail, à la modernisation du dialogue social et à la sécurisation desparcours professionnels/ley relativa al trabajo, la modernización del diálogo social y las garantías en las carreras profesionales ${ }^{18}$.

Tal y como se establece en el apartado $7^{\circ}$ del artículo L 2242-8, modificado por la Ordenanza $\mathrm{n}^{\circ} 2017-1385$ de 22 septiembre de 2017 referido a la negociación anual sobre la igualdad profesional entre mujeres y hombres y la calidad de vida en el trabajo, conocida como NAO (Négociation Annuelle Obligatoire $)^{19}$. Se dispone la obligación de negociar: “(...) las modalidades del pleno ejercicio por el trabajador de su derecho a la desconexión y la puesta en marcha por la empresa de dispositivos de regulación de la utilización de los dispositivos digitales, a fin de asegurar el respeto del tiempo de descanso y vacaciones, así como de su vida personal y familiar. A falta de acuerdo, el empleador, previa audiencia del comité de empresa o, en su defecto, de los delegados de personal, elaborará una política de actuación al respecto. Esta política definirá las modalidades de ejercicio del derecho a la desconexión y preverá, además, la puesta en marcha de acciones de formación y sensibilización sobre uso razonable de los dispositivos digitales, dirigida a los trabajadores, mandos intermedios y dirección". Como se puede apreciar, la ley reconoce dos instrumentos donde se puede regular esta materia: una, el convenio colectivo, y a falta de éste, una política de actuación elaborada de la empresa.

\subsubsection{Convenio colectivo}

En cuanto al pacto en el convenio colectivo deberían tratarse: a) las "modalidades" del pleno ejercicio del derecho a la desconexión; b) la puesta en marcha por la empresa de "dispositivos" de regulación de la utilización de "dispositivos digitales". Todo lo anterior dirigido a un objetivo: "asegurar el respeto del tiempo de descanso y de vacaciones, así como de su vida personal y familiar".

Por esto, no nos parece que se pueda calificar de un derecho inconcreto ${ }^{20}$, toda vez que tiene una finalidad definida, cual es, que se respete aquel "tiempo" en que el trabajador no está sujeto a su jornada, que coincide con aquel destinado al descanso y vacaciones, y que trasunta directamente con la "vida personal y familiar". Ciertamente, la finalidad es evitar que se perturbe aquel espacio del trabajador que le pertenece exclusivamente, en contraposición a aquel en que debe prestar servicios al empleador. De esta suerte, es posible afirmar que el derecho a la desconexión laboral puede ser entendido como el derecho de los trabajadores, cualquiera que sea su categoría, a desconectarse, es decir a no estar permanentemente accesible por razones relacionadas con la ejecución de su trabajo más allá de la jornada laboral. Así las cosas, el derecho a la desconexión se configura, por tanto, como el derecho a desconectarse del trabajo (garantizando el respeto por el descanso, las vacaciones, la vida personal) frente a las intromisiones de terceros fuera del tiempo de trabajo.

Respecto de las "modalidades" indicadas, dice relación con todas aquellas medidas que la empresa está obligada a implementar con miras de respetar aquel "tiempo" en que el trabajador no está sujeto a su jornada. Pensamos que ellas pueden presentar dos grandes clases: unas, deben ser jurídicas, y, otras, de orden material. En relación a las jurídicas, consideramos que básicamente tienen que apuntar en dos direcciones. La primera destinada a establecer la obligación, respecto de trabajadores, en especial jefes de áreas, de "no" enviar comunicaciones o requerimientos a sus subordinados fuera de sus horarios de trabajo. La segunda destinada a reforzar el derecho de los trabajadores de no contestar dichas comunicaciones o requerimientos durante sus tiempos de descanso.

\footnotetext{
18 JORF Nº184 du 9 août 2016.

19 Debe tenerse en cuenta que en Francia es obligatorio que las empresas que cuenten con representación sindical negocien anualmente con los representantes de los trabajadores sobre retribuciones, tiempo de trabajo, reparto del valor añadido en la empresa, calidad del trabajo e igualdad profesional entre hombre y mujeres

20 Véase Cristóbal Molina Navarrete, “Jornada laboral y tecnologías de la infocomunicación: 'desconexión digital', garantía del derecho al descanso", Temas laborales: Revista andaluza de trabajo y bienestar social, No 138, 2017, 272.
} 
Decíamos también que debían existir modalidades materiales. Creemos que éstas dicen relación con la puesta en marcha de los dispositivos digitales, antes mencionados, a los que hace referencia la ley. Estos pueden ser de variada índole, a saber: efectuar ajustes en los servidores de las empresas que impidan a los trabajadores reciban comunicación electrónica después de sus horarios de trabajo; incorporar aplicaciones en los smartphones que logren el mismo resultado tratándose de mensajes de textos, cualquiera sea la vía utilizada (p. ej. WhatsApp); implantar sistemas tecnológicos que limiten o impidan el acceso de los trabajadores a sus dispositivos digitales fuera del horario de trabajo.

\subsubsection{Reglamentación interna}

El derecho a la desconexión no forma parte del contenido obligatorio del convenio, sino del proceso negociador ${ }^{21}$. De esta forma, la obligación es de negociar, pero no de lograr un acuerdo ${ }^{22}$. Y es que, si éste no se obtiene, no se contempla un régimen legal supletorio, sino, más bien, se genera la obligación para el empleador de elaborar "una política de actuación al respecto" (francés). Ahora bien, en forma previa a confeccionar dicho documento, se debe consultar la opinión del comité de empresa o, en su defecto, de los delegados de personal, sobre el proyecto de regulación. Pero esta consulta a los representantes de los trabajadores no tiene carácter vinculante, por tanto, la posición de éstos no necesariamente terminará reflejándose en la política en cuestión.

Como se aprecia, la falta de un acuerdo en la negociación colectiva, necesariamente deviene en un instrumento unilateral del empresario. Se sostiene así que éste debe redactar una carta a modo de declaración formal, más o menos detallada en la que la empresa expone su filosofía, propósito, principios y valores, después de consultar al comité social y económico. Esta carta definirá los procedimientos para el ejercicio del derecho a la desconexión y proporciona además la implementación, para los empleados y el personal de gestión y dirección y de acciones de capacitación y sensibilización para el uso razonable de herramientas digitales 23 .

Más allá de la naturaleza jurídica de esta carte d'entreprise, ya que, si bien parece ser un instrumento configurado como una base mínima para la aplicación del derecho a desconectarse dentro de la empresa, debe entenderse que se trata de un documento con fuerza vinculante para las partes a modo de reglamento interior que obliga, entre otras cuestiones, a dar contenido a este derecho, respetarlo, establecer instrumentos que lo garanticen y cauces para su reclamación.

\subsubsection{Aplicación de la ley}

La concreción de este derecho durante el año largo de vigencia es ciertamente limitado, no en vano, en la mayoría de los casos se ha optado, tal y como más adelante tendremos ocasión de apreciar, por limitar la contestación de correos electrónicos o llamadas telefónicas fuera de las horas de trabajo o en fin de semana como es el caso de grandes empresas como Michelin (en Francia) al igual que lo hizo el grupo Volkswagen en Alemania que ha establecido el cierre rotundo de sus servidores de correos entre las 6:15 p.m. y las 7 a.m.

Por su parte la empresa La Poste que en el 2015 (antes entrada en vigor de la normativa de la desconexión laboral) dio luz verde a un acuerdo de empresa sobre un "derecho a desconectar, fuera del

\footnotetext{
21 Ídem.

22 Ídem.

${ }^{23}$ Véase artículo L2242-17 del Código del Trabajo francés: "7 Les modalités du plein exercice par le salarié de son droit à la déconnexion et la mise en place par l'entreprise de dispositifs de régulation de l'utilisation des outils numériques, en vue d'assurer le respect des temps de repos et de congé ainsi que de la vie personnelle et familiale. A défaut d'accord, l'employeur élabore une charte, après avis du comité social et économique. Cette charte définit ces modalités de l'exercice du droit à la déconnexion et prévoit en outre la mise en œuvre, à destination des salariés et du personnel d'encadrement et de direction, d'actions de formation et de sensibilisation à un usage raisonnable des outils numériques”.
} 
horario de trabajo". Una fórmula muy simple que tiene como objetivo proteger a los empleados fuera de su horario comercial. Sin embargo, este acuerdo también estipuló la necesidad de ser reactivo en caso de que "la gravedad, la urgencia o una importancia excepcional justifiquen el uso de mensajes profesionales por la noche o fuera de los días trabajados", por lo tanto, introdujo ciertas excepciones de clara naturaleza "subjetiva" al derecho a desconectarse que, en gran parte, lo desdibujan.

Teniendo en cuenta esta falta de concreción del derecho a la desconexión en Francia es necesario, tal y como sostiene MOREL, distinguir dos aspectos del mismo: el derecho a desconectarse en el trabajo (para resolver los problemas derivados de la hiperconexión) y el derecho a desconectarse del trabajo (para garantizar períodos de descanso, vacaciones y vida personal). Al considerar los períodos de descanso y la vida personal, la ley establece el derecho a desconectarse del trabajo e incorporando este derecho en la cuestión de la calidad de vida en el trabajo, establece también la desconexión en el trabajo, para cuestionarse si el marco legislativo francés puede alcanzar estos dos objetivos, llegando a la conclusión de que el marco francés termina siendo insuficientemente coordinado con el tiempo y la regulación de la carga de trabajo ${ }^{24}$.

En ocasiones los problemas de conexión fuera del horario de trabajo y del lugar de trabajo, están estrechamente vinculados a la hiperconexión o la necesidad de estar conectado a internet y/o al correo electrónico que los trabajadores sufren en el puesto de trabajo y que afecta al conjunto de la sociedad más allá del trabajo que se ha convertido en una obsesión-adicción que puede agotarnos psicológicamente e incluso provocar estrés ${ }^{25}$, dando lugar a enfermedades nuevas como la nomofobia ${ }^{26}$, no en vano, con el desarrollo de las tecnologías, han nacido nuevas fobias que se relacionan directamente con la innovación de los dispositivos electrónicos y su uso intensivo.

\section{El derecho a la desconexión en España}

Tomando como referencia el caso francés, en España también ha habido avances significativos en los últimos años sobre la regulación inicialmente convencional y más recientemente legislativa del derecho a la desconexión laboral.

Dada esta realidad de la conectividad permanente que ha supuesto la necesidad de respetar los límites de la duración de la jornada de trabajo, se ha optado por introducir en el marco de la negociación colectiva y, más recientemente, en el marco legislativo el derecho a la desconexión laboral considerado como la limitación al uso de las tecnologías de la comunicación más allá de la jornada de trabajo para garantizar el tiempo de descanso y vacaciones de los trabajadores.

\subsection{Convenios colectivos}

A partir del ejemplo de Francia y haciéndose eco de la regulación introducida en ese país ha habido en España algunos casos o ejemplos de empresas que han optado por regular la desconexión digital, como el sucedido en la empresa de seguros AXA por el que, en su convenio, firmado en fecha de

\footnotetext{
24 Laëtitia Morel, “Le droit à la déconnexion en droit français : la question de l'effectivité du droit au repos à l'ère du numérique”, Labor \& Law Issues, vol. 3, No 2, 2017, 1-16, texto disponible en : https://halshs.archives-ouvertes.fr/halshs-01684561.

${ }_{25}$ Hyperconnection and its Consequences. Exploring your mind. (November 2, 2018)

https:// exploringyourmind.com/hyperconnection-and-its-consequences/

26 "No-mobile-phone phobia", nombre con el que se ha defendido al medio a estar sin móvil. la incomunicación nos puede llegar a producir una sensación de ansiedad que nos invade y nos hace desear intensamente el momento en que volvamos a estar conectados.
}

Modalidad de publicación continua / Continuous publication modality 
21 de julio de 2017 se reconoce, en su articulado, el derecho a la "desconexión digital" 27 28. Tal y como se establece en este artículo 14 que lleva por rúbrica "Derecho a la desconexión digital":

Los cambios tecnológicos producidos en las últimas décadas han provocado modificaciones estructurales en el ámbito de las relaciones laborales. Es innegable que hoy en día el fenómeno de la interconectividad digital está incidiendo en las formas de ejecución del trabajo mudando los escenarios de desenvolvimiento de las ocupaciones laborales hacia entornos externos a las clásicas unidades productivas: empresas, centros y puestos de trabajo.

En este contexto, el lugar de la prestación laboral y el tiempo de trabajo, como típicos elementos configuradores del marco en el que se desempeña la actividad laboral, están diluyéndose en favor de una realidad más compleja en la que impera la conectividad permanente afectando, sin duda, al ámbito personal y familiar de los trabajadores.

Es por ello que, las partes firmantes de este Convenio coinciden en la necesidad de impulsar el derecho a la desconexión digital una vez finalizada la jornada laboral. Consecuentemente, salvo causa de fuerza mayor o circunstancias excepcionales, AXA reconoce el derecho de los trabajadores a no responder a los mails o mensajes profesionales fuera de su horario de trabajo.

Como puede apreciarse, se recoge, por primera vez, en España en el marco de un Convenio colectivo el derecho a la desconexión digital. Igualmente, en España, más recientemente la empresa Ikea ha firmado un acuerdo con el sindicato de comercio FETICO (Federación de trabajadores independientes de comercio) para mejorar las condiciones laborales de sus trabajadores en España por lo que respecta a los horarios. Así, a partir de septiembre de 2018, se prevé incluir más fines de semana libres al año, catorce en lugar de seis, diez en el caso de los trabajadores a tiempo parcial, también disminuir el porcentaje de domingos y festivos a trabajar, de 23 a 19, teniendo especial importancia la elección en tres fechas de la campaña de Navidad como son Nochebuena, el 30 de diciembre y el 5 de enero. También se garantizarán dos días de descanso todas las semanas, eliminando las semanas de seis días laborables.

Para promover de forma voluntaria las vacaciones de verano fuera del periodo estival, esta multinacional sueca abonará 180 euros semanales a los trabajadores/as que las cojan entre los meses de enero y mayo. En el marco de estas sustanciales mejoras de los horarios y, en general, del tiempo de trabajo se reconoce el derecho a ignorar los emails, mensajes o llamadas del jefe fuera del horario laboral. Se trata de una iniciativa novedosa en el sector de la gran distribución, un sector con condiciones especialmente duras para los trabajadores tanto por los horarios de trabajo (domingos, festivos, noches) como por los bajos salarios y los tipos de contratos (a tiempo parcial en un porcentaje muy significativo).

Por su parte, el II Plan de igualdad de Hipermercados Carrefour registrado por Resolución de 8 de enero de 2019, de la Dirección General de Trabajo ${ }^{29}$, se alude a efectos de garantizar que el disfrute de las medidas de conciliación no afecte a las oportunidades de desarrollo profesional, a la necesidad de estudiar medidas que faciliten la conciliación también de los grupos de mandos y equipo directivo, tales como la desconexión digital, rango horario de las reuniones dentro y fuera de la empresa ${ }^{30}$.

27 Resolución de 21 de septiembre de 2017, de la Dirección General de Empleo, por la que se registra y publica el Convenio colectivo del Grupo Axa, BOE de 10 de octubre de 2010. Véase el texto íntegro en: https://www.boe.es/diario boe/txt.php?id=BOE-A-2017-11622

28 Para consultar convenios colectivos, véase la Base de datos de Convenios colectivos (consulta pública) disponible en: https://expinterweb.empleo.gob.es/regcon/pub/consultaPublicaEstatal.

29 BOE, de 26 de enero de 2019.

30 En un sentido muy parecido con anterioridad, el Plan de Igualdad incluido en XVI Convenio colectivo de la ONCE y su personal, en su apartado de conciliación de la vida laboral con la personal y profesional, se hace referencia a que las partes valoran, como medida que promueve la efectiva conciliación de la vida personal, laboral y familiar, la denominada «desconexión digital» aplicada a herramientas de índole tecnológica e informática, como teléfonos y tablets con conexión de datos y 
Unas de las últimas empresas que a fecha de elaboración de este trabajo (junio de 2018) se ha sumado al derecho a la desconexión laboral ha sido el Banco Santander que ha alcanzado en España un acuerdo con los sindicatos para reconocer el derecho de los trabajadores a no responder a emails o mensajes profesionales fuera de sus horarios de trabajo, ni durante los tiempos de descanso, permisos, licencias o vacaciones, salvo causa de fuerza mayor o circunstancias excepcionales. El objetivo fundamental es el de incorporar nuevas medidas de adaptación de las relaciones laborales al nuevo entorno digital, y asegurar el respeto del tiempo de vacaciones y de descanso, así como la vida personal y familiar.

Se pretende, también, promover el uso de la tecnología, con acciones de sensibilización para un uso razonable y responsable, para facilitar la optimización del tiempo de trabajo y fomentar la racionalización del tiempo de los profesionales en reuniones.

\subsection{Iniciativas legislativas}

En España, el partido actualmente en el gobierno, Partido Socialista Obrero Español (PSOE), cuando todavía era oposición al gobierno del Partido Popular, como consecuencia del éxito de una moción de censura, presentó el pasado 18 de abril de 2018 una serie de enmienda a la reforma de la Ley de Protección de Datos, en la que planteaba, entre otras (enmienda núm. 307) regular el derecho de los trabajadores a no responder a correos y mensajes electrónicos en su tiempo de ocio, buscando reconocer por ley el derecho del trabajador a desconectar fuera del horario laboral. En concreto, se proponía la inclusión de un nuevo artículo al Proyecto de Ley Orgánica de Protección de Datos de Carácter Personal donde se recogiera el derecho a la desconexión digital.

La aprobación el pasado día 5 de diciembre de 2018 de la Ley Orgánica 3/2018, de 5 de diciembre, de Protección de Datos Personales y garantía de los derechos digitales ${ }^{31}$, incorpora en el Título $\mathrm{X}$ de esta ley donde se reconoce y garantiza un elenco de derechos digitales de los ciudadanos conforme al mandato establecido en la Constitución española. A su vez, su art. 88 contiene, en particular, el reconocimiento del derecho a la desconexión digital en el ámbito laboral. De este modo, se convierte en la primera referencia expresa de carácter normativo por la que se regula la desconexión laboral en España $^{32}$. Así en el citado artículo bajo la rúbrica del derecho a la desconexión digital en el ámbito laboral, se establece que:

1. Los trabajadores y los empleados públicos tendrán derecho a la desconexión digital a fin de garantizar, fuera del tiempo de trabajo legal o convencionalmente establecido, el respeto de su tiempo de descanso, permisos y vacaciones, así como de su intimidad personal y familiar.

2. Las modalidades de ejercicio de este derecho atenderán a la naturaleza y objeto de la relación laboral, potenciarán el derecho a la conciliación de la actividad laboral y la vida personal y familiar y se sujetarán a lo establecido en la negociación colectiva o, en su defecto, a lo acordado entre la empresa y los representantes de los trabajadores.

ordenadores portátiles, compartiendo que su utilización no ha de ser motivo ni argumento para la extensión de la jornada laboral, ni para la interrupción de los tiempos de descanso o licencias de los trabajadores y trabajadoras (BOE, de 18 de enero de 2018). En este mismo sentido, el artículo 46 del Convenio colectivo de Philips Ibérica, SAU (BOE, de 8 de diciembre de 2018), de forma expresa establece que: "para favorecer la conciliación de la vida personal y profesional, y garantizar el descanso de los empleados, se reconoce el derecho a la desconexión digital una vez finalizada la jornada laboral del empleado. Facultad de desconexión de los dispositivos digitales, no responder emails, mensajes y llamadas profesionales fuera de su horario de trabajo, salvo causa de fuerza mayor".

31 BOE, de 6 de diciembre de 2018.

$32 \mathrm{El}$ art. 89 de esta Ley está dedicado a regular el derecho a la intimidad frente al uso de dispositivos de video-vigilancia y de grabación de sonidos en el lugar de trabajo, mientras que el art. 90 contempla el derecho a la intimidad ante la utilización de sistemas de geolocalización en el ámbito laboral 
3. El empleador, previa audiencia de los representantes de los trabajadores, elaborará una política interna dirigida a trabajadores, incluidos los que ocupen puestos directivos, en la que definirán las modalidades de ejercicio del derecho a la desconexión y las acciones de formación y de sensibilización del personal sobre un uso razonable de las herramientas tecnológicas que evite el riesgo de fatiga informática. En particular, se preservará el derecho a la desconexión digital en los supuestos de realización total o parcial del trabajo a distancia, así como en el domicilio del empleado vinculado al uso con fines laborales de herramientas tecnológicas.

Se añade, igualmente, a través de la disposición final decimotercera de esta Ley, un nuevo artículo 20 bis al texto refundido de la Ley del Estatuto de los Trabajadores, aprobado por Real Decreto Legislativo 2/2015, de 23 de octubre, donde se reconoce, de manera expresa, el derecho a la desconexión, estableciéndose que:

Los trabajadores tienen derecho a la intimidad en el uso de los dispositivos digitales puestos a su disposición por el empleador, a la desconexión digital y a la intimidad frente al uso de dispositivos de video-vigilancia y geolocalización en los términos establecidos en la legislación vigente en materia de protección de datos personales y garantía de los derechos digitales ${ }^{33}$.

El texto propuesto pretende garantizar el derecho de los trabajadores a no tener que responder comunicaciones electrónicas fuera de su jornada legal de trabajo para garantizar así el respeto a su tiempo de descanso y vacaciones, así como de su intimidad personal y familiar.

El art. 88 de la Ley Orgánica 3/2018, de 5 de diciembre, de Protección de Datos de Carácter Personal, insta a las empresas a elaborar, previa audiencia de los representantes de los trabajadores, protocolos internos (una política interna) sobre las distintas modalidades de ejercicio de este derecho de desconexión digital, dentro de la negociación colectiva. También promueve a realizar acciones para evitar el síndrome de "fatiga informática" entre la plantilla, en los supuestos de realización total o parcial del trabajo a distancia y especialmente cuando el uso de dispositivos digitales se produzca en el domicilio de los trabajadores.

El derecho a la desconexión laboral se enmarca dentro de los 15 derechos fundamentales para la era digital propuestos por el PSOE no en vano, defienden que la era digital debe incorporar nuevos derechos y libertades, como la desconexión digital, el derecho al olvido, la privacidad de las comunicaciones o el derecho a la portabilidad.

Con anterioridad a esta propuesta el grupo parlamentario de Unidos Podemos-En Comú PodemEn Marea, ya había registrado una iniciativa al respecto al presentar en el pasado 22 de marzo del 2017 una iniciativa legislativa sobre el derecho a la desconexión laboral fuera del horario de trabajo, para su debate en la Comisión de Empleo y Seguridad Social.

Tal y como se señala en este texto: "el advenimiento de las nuevas tecnologías en los últimos tiempos ha revolucionado el mundo laboral, permitiendo nuevos esquemas organizativos que han hecho tambalear el concepto de descanso y la garantía del mismo, y las últimas reformas laborales han facilitado mecanismos de desregulación y dilatación de las jornadas de trabajo. Si bien es cierto que las nuevas tecnologías han aportado nuevas oportunidades de flexibilidad, como la posibilidad de trabajar a distancia

${ }^{33}$ En este mismo sentido, la disposición final decimocuarta, referida a la modificación del texto refundido de la Ley del Estatu to Básico del Empleado Público, añade una nueva letra j bis) en el artículo 14 del texto refundido de la Ley del Estatuto Básico del Empleado Público, aprobado por Real Decreto Legislativo 5/2015, de 30 de octubre, que quedará redactada como sigue: “ $j$ bis) A la intimidad en el uso de dispositivos digitales puestos a su disposición y frente al uso de dispositivos de video-vigilancia y geolocalización, así como a la desconexión digital en los términos establecidos en la legislación vigente en materia de protección de datos personales y garantía de los derechos digitales", 
y de facilitar las comunicaciones en grupo, no lo es menos que también borran las fronteras entre la vida personal y la profesional, generando por ello tiempos de disponibilidad que no deberían existir pues no respetan las jornadas pactadas y remuneradas, y que además, pueden llegar a tener un impacto negativo en la salud de los trabajadores y trabajadoras. Sin ir más lejos, un reciente estudio publicado en octubre de 2016 en Francia, indica que ya es un $37 \%$ de la población activa la que usa sus herramientas digitales profesionales fuera de los horarios de trabajo y que un $62 \%$ estaría de acuerdo en que se regulara"

Iniciativa legislativa que incluso va un poco más allá de la iniciativa francesa al exigir la desconexión por ley, al proponer impulsar una regulación legal conjuntamente con los agentes sociales del uso de las tecnologías de la comunicación (mensajería y correos electrónicos o dispositivos móviles) fuera de la jornada laboral con el objetivo de evitar que los trabajadores y trabajadoras puedan continuar trabajando después de finalizar su jornada laboral utilizando los medios electrónicos de la empresa, y garantizar la seguridad y salud en el trabajo y el descanso necesario, mediante la limitación de la jornada laboral y el respeto a las vacaciones de las personas trabajadoras así como también Impulsar la creación de un plan de uso de las tecnologías de la comunicación fuera de la jornada laboral con el objetivo de educar digitalmente tanto al empresariado como a los trabajadores y trabajadoras y la realización de un estudio que analice si el uso intensivo de las tecnologías de la información y de la comunicación (mensajería y correos electrónicos o dispositivos móviles) puede llegar a provocar problemas de adicción o dependencia y la creación por parte del Instituto Nacional de Estadística de indicadores de medición del estrés laboral de los trabajadores y trabajadoras ${ }^{34}$.

Por su parte el 7 de abril de 2017, el partido socialista presentó una proposición de ley sobre protección de los derechos digitales de la ciudadanía donde se recoge el derecho a la desconexión laboral ${ }^{35}$, instando al Gobierno a presentar un Proyecto de Ley para reformar el régimen laboral vigente a fin de garantizar el derecho a la desconexión digital de los trabajadores fuera del horario laboral.

\subsection{Reconocimiento judicial}

Como primer precedente en España podemos citar la sentencia de la Audiencia Nacional de fecha 17 de julio de 1997, en la cual se analizaba un supuesto en el que la empresa requería a su personal comercial tener conectado en todo momento el teléfono móvil. La Audiencia nacional declaró la nulidad de las instrucciones de la empresa que obligan a sus trabajadores a mantener fija la atención a los teléfonos móviles una vez concluida la jornada de trabajo de cada uno de ellos. Y se concluye así que la conexión ininterrumpida de los teléfonos móviles sobrepasaba las facultades empresariales, pudiendo resultar perjudicados los trabajadores en sus legítimos derechos e intereses.

Cabe subrayar, asimismo, la sentencia de 28 de enero de 2014 ( $N^{o}$ de Recurso: 428/2013) de la Audiencia Nacional, que consideró abusiva la cláusula del contrato de trabajo en la que se obligaba a un trabajador a disponer de medios propios (móvil e internet) y a proporcionárselos a la empresa, para que ésta pudiera enviarle cualquier tipo de comunicación referida a su relación laboral, ya fuera en períodos dentro o fuera de la jornada laboral ${ }^{36}$.

Coincidimos con este criterio, pues la desconexión es también el derecho del trabajador a conocer su jornada de trabajo, su horario y el tiempo a disposición del empresario, porque fuera del establecimiento del mismo. La intromisión del empresario consistente en llamar o comunicarse con el trabajador vía e-mail, una llamada al móvil, mandándole un whatsapp, es una vulneración del empresario

\footnotetext{
34 Véase el texto de la Proposición No de Ley en: http://www.congreso.es/public oficiales/L12/CONG/BOCG/D/BOCG12-D-127.PDF, 52-54.

35 Véase el texto de la proposición no de ley en: http://www.congreso.es/public oficiales/L12/CONG/BOCG/D/BOCG12-D-127.PDF pp52.54. Boletín Oficial Cortes Generales. Congreso de los Diputados, serie D, núm. 139, de 07/04/2017 en http://www.congreso.es/public_oficiales/L12/CONG/BOCG/D/BOCG-12-D-139.PDF p 4-6.

${ }^{36}$ ROJ: SAN 239/2014
} 
del tiempo de trabajo. Es importante subrayar que el trabajador tiene derecho al descanso diario, semanal, y mensual, y a conocer la concreción de su jornada de trabajo.

Tal y como se establece en la Sentencia TSJ castilla León (Valladolid) de 3 de febrero de 2016 ${ }^{37}$ al abordar el tema del control empresarial de la jornada de trabajo en los supuestos de teletrabajo: el tiempo de trabajo en el domicilio es tiempo de trabajo exactamente igual que el realizado fuera del mismo. El control del tiempo de trabajo es responsabilidad de la empresa, que debe igualmente registrar la jornada del trabajador día a día y totalizarla en el período fijado para el abono de las retribuciones, entregando copia del resumen al trabajador en el recibo correspondiente (véase art. 35.5 del Estatuto de los Trabajadores).

El respeto de los límites de jornada y descansos forma parte del derecho del trabajador a la protección de su seguridad y salud (Directiva 2003/88/CE), que es responsabilidad del empresario, a partir de la obligada evaluación de riesgos y planificación de la actividad preventiva. Aunque el trabajador preste su trabajo en su domicilio corresponde a la empresa establecer las pautas necesarias sobre tiempo de trabajo para garantizar el cumplimiento de los límites de jornada y descansos.

\section{Proyecto de ley sobre el derecho de desconexión en Chile}

\subsection{Sobre su objetivo y contenido}

Todo lo expuesto con anterioridad ha tenido repercusión en Chile. Actualmente se encuentra en tramitación un proyecto de ley (Boletín $\left.\mathrm{N}^{\circ} 11.208-13\right)$, titulado "sobre la protección de los derechos de los trabajadores en la era digital", donde uno de los apartados de su mensaje se denomina "el derecho a la desconexión de los trabajadores en la era digital". En este apartado se advierte que "(...) las exigencias de un entorno laboral cada vez más hostil al descanso", donde proliferan "jefaturas hiperconectadas, que someten a sus subalternos a su propio ritmo, enviando e-mails y mensajes fuera de horarios de trabajo y esperando una respuesta inmediata, sin tener conciencia del impacto que esto puede tener en el destinatario y su entorno".

Tomando en cuenta esta situación, el mensaje destaca la dictación en Francia de la ley El Khomri. La Ley 2016/1088, de 8 de agosto de 2016, conocida también como Loi Travail, como la primera ley que establece este derecho a la desconexión, que hemos analizado previamente. Asimismo, el mensaje da cuenta de las iniciativas que existían en España sobre esta materia promovidas por el PSOE y Comú Podem, y que finalmente, como explicamos se materializaron en la ley española, antes explicada. Se observa entonces como estas iniciativas legales francesa y española han tenido una influencia directa en Chile.

La propuesta legal chilena contempla la incorporación de un nuevo artículo al Código del Trabajo (en adelante, "CdT"), que sería el art. 22 bis CdT, y la modificación del $\mathrm{N}^{\circ} 2$ del art. 154 del mismo cuerpo legal. La primera norma citada tendría el siguiente tenor:

Los trabajadores tendrán el derecho a la desconexión, por el cual no estarán obligados a responder, fuera de la jornada de trabajo, comunicaciones de sus empleadores o jefaturas, proveedores, clientes o consumidores con que se relacione la empresa o establecimiento, obra o faena, cualquiera sea el medio a través del cual éstas se realicen. El derecho consagrado en el inciso anterior, tendrá lugar también durante el período de descanso de la jornada diaria, semanal o compensatorio; mientras el trabajador este en uso de su feriado anual, utilizando los permisos a los cuales el trabajador accediere o gozando de fuero.

Con todo, los trabajadores a que se refiere el artículo 305 del Código del Trabajo podrán acordar con el empleador responder, de manera excepcional, comunicaciones

37 ROJ: STSJ CL 281/2016. 
que estén descritas detalladamente en el respectivo contrato, vayan asociados a beneficios específicos para los trabajadores y no constituyan una renuncia absoluta al derecho o que lo limiten de manera irracional o desproporcionada.

Por su parte, el actual $\mathrm{N}^{\circ} 2$ del art. $154 \mathrm{CdT}$ dispone que "el reglamento interno deberá contener, a lo menos, las siguientes disposiciones: (...) 2.- los descanso”. Decíamos que este numeral segundo se pretende modificar, y el contenido propuesto sería:

...los descansos y el derecho a desconexión de los trabajadores fuera de la jornada de trabajo lo que implica la implementación de procedimientos, aplicativos y dispositivos que para regular el uso de las herramientas digitales con el fin de garantizar el cumplimiento de los períodos de descanso.

Como se puede apreciar, la propuesta legislativa apunta a proteger el derecho de los trabajadores a distintos tipos de descansos, estos son, diarios, semanales, y anuales ${ }^{38}$. ¿De qué se les busca proteger?, pues precisamente que los mismos no sean alterados o interrumpidos. ¿Cómo se pueden alterar o interrumpir? por cualquier clase de comunicación, no sólo se circunscribe a mensajes de carácter electrónico (e-mail, whatssap, etc.), sino también podrían ser llamadas telefónicas, etc. ¿Quiénes puede efectuar dichas comunicaciones? empleadores o jefaturas, proveedores, clientes o consumidores con que se relacione la empresa o establecimiento, obra o faena. A continuación, analizaremos cada una de estas afirmaciones.

\subsection{Protección de los descansos por alteraciones o interrupciones}

La norma propuesta apunta a proteger a los trabajadores respecto del tiempo que se encuentra fuera de la jornada de trabajo, en orden a que éste no sea interrumpido o alterado por comunicaciones de ninguna clase. El tiempo fuera de la jornada coincide con los denominados períodos de descanso en el trabajo. Por ello, llama la atención que se indique que la protección no sólo se extiende a los lapsos fuera de jornada, sino también "durante el período de descanso de la jornada diaria, semanal o compensatorio; mientras el trabajador esté en uso de su feriado anual utilizando los permisos a los cuales el trabajador accediere o gozando de fuero".

Como señala el autor español CABEZA PEREIRO, la diferencia entre tiempo de trabajo y de descanso no admite graduaciones: "o se está trabajando o no se está trabajando, y por lo tanto, se está descansando" 39 . Bajo este criterio, entonces, parece una redundancia que junto con la protección del tiempo fuera de jornada, se añadan los períodos de descansos, porque ambos se encuadran en el mismo lapso de tiempo, es decir, espacios en los que no se está bajo el poder de dirección del empleador. Autores nacionales como GAMONAL y GUIDI califican dichos espacios como un derecho de los trabajadores al "tiempo libre" 40 . Por tales motivos, nos parece más aconsejable que la norma propuesta, en vez de hacer dicha distinción -entre tiempo fuera del trabajo y descansos-, más bien, se plateara en términos de proteger los tiempos fuera del trabajo, dentro de los que se incluyen, entre otros, los descansos, los permisos legales y convencionales, etc.

Según indicábamos, la protección apunta a evitar que los trabajadores sufran alteraciones o interrupciones durante el tiempo fuera de la jornada, en particular, sus descansos. La forma de afectar

\footnotetext{
38 Sobre los descansos véase Rojas Miño, op. cit., 206ss.; Gamonal y Guidi, op. cit., 193ss, y LizAma PorTAL, Luis, y Luis Lizama y Diego Lizama, Manual de Derecho individual de Trabajo, Santiago, Ediciones DER, 130ss.

${ }^{39}$ Jaime Cabeza Pereiro, "Las fuentes reguladoras de la jornada de trabajo", Joaquín Aparicio y Juan López (coords.), Tiempo de trabajo, Albacete, Bomarzo, 2007, 16.

40 Gamonal y Guidi, op. cit., 172.
} 
esos lapsos es a través de comunicaciones de cualquier tipo, que provengan de "empleadores o jefaturas, proveedores, clientes o consumidores" de la empresa.

Decimos "alteraciones" o "interrupciones", ya que una comunicación - p. ej. un correo electrónico-, sobre todo que provenga del empleador o una jefatura, va implicar que el trabajador destinatario, al menos, suspenda su tiempo de descanso para leerlo y reflexionar sobre el mismo, con la finalidad de dar respuesta a un eventual requerimiento, aun cuando ella luego se efectúe durante la jornada. Ese momento dedicado a leer y pensar significa, sin duda, una "alteración" del descaso. Pues éste no puede desarrollarse con autonomía frente a la esfera empresarial, que permea un espacio donde no puede inmiscuirse. El trabajador no dispondría de su tiempo, sino que volvería a estar "conectado" con su trabajo en un periodo de descanso. Ahora bien, dicha conexión puede llegar a ser más intensa, si la comunicación requiere del trabajador que lleve a cabo alguna tarea, aun cuando no se ejecute en la empresa, como puede ser el propio domicilio. En este caso, preferimos decir que el descanso se "interrumpe", ya que tal solicitud no sólo lo obliga a estar "conectado", sino, más bien, a volver a trabajar. De esta suerte, aquí el poder de dirección del empleador desnaturaliza por completo el tiempo del cual dispone el trabajador, ya que lo deja sin efecto. La forma de protección que se propone frente a estas comunicaciones, nos parece que puede dividirse en dos.

\subsubsection{Derecho a no contestar}

Ciertamente, se define así el derecho a desconexión, pues se conceptúa como aquel por el cual los trabajadores "no estarán obligados a responder, fuera de la jornada de trabajo" (cfr. nuevo art. 22 bis propuesto por el proyecto de ley).

\subsubsection{Utilización de dispositivos que amparen la desconexión}

¿Es posible afirmar que existe una desconexión del trabajo, si se siguen recibiendo mensajes más allá de la jornada laboral, no obstante que el trabajador tenga el derecho a no responder? A lo menos una desconexión desde el punto de gramatical no se consigue. Cabe indicar que la palabra "desconectar", en la acepción que nos interesa, importa "interrumpir la conexión entre dos o más cosas" 41 , o "dejar de tener relación, comunicación, enlace, etc." ${ }^{2}$. Es evidente que, si al trabajador se le envían mensajes fuera de su horario de trabajo -aunque no los conteste- no es posible decir que se interrumpió la conexión -la relación, la comunicación, o enlace- entre trabajador y trabajo. Toda vez que se produce igualmente una alteración del descanso del trabajador, según explicábamos.

En virtud de lo expuesto, para que sea realmente efectivo este derecho de desconexión se requeriría, no sólo que no exista la obligación de no responder, sino asimismo la de no enviar comunicaciones fuera de la jornada de los trabajadores. Si bien esta prohibición no se contempla en el proyecto de ley de forma expresa, es posible deducir que ésta debiera estar contemplada en el reglamento interno de las empresas. Recordemos que el proyecto pretende modificar el actual n ${ }^{\circ} 2$ del art. $154 \mathrm{CdT}$, en orden que este reglamento contenga: “(...) el derecho a desconexión de los trabajadores fuera de la jornada de trabajo lo que implica la implementación de procedimientos, aplicativos y dispositivos que para regular el uso de las herramientas digitales con el fin de garantizar el cumplimiento de los períodos de descanso".

Como se observa, el reglamento deberá regular los procedimientos y la aplicación de dispositivos sobre el uso de herramientas digitales para asegurar que no exista una intromisión de la empresa en los tiempos fuera de jornada. Este proyecto de norma confirma que el derecho a desconexión exige también

\footnotetext{
${ }^{41}$ Real Academia Española, Diccionario de la Lengua Española, 23ª edición, 2014, voz “desconectar”, segunda acepción. Disponible en: http://dle.rae.es/?id=GilsITP

42 Ibid., voz "desconectar", quinta acepción.
} 
de la empresa una acción positiva con miras a garantizar este derecho. Si hablamos de una intervención de la empresa en esta cuestión: primero, es obvio que no puede obligar a sus trabajadores a responder comunicaciones del entorno del trabajo; segundo, habría que procurar que tales comunicaciones no lleguen a destino durante los tiempos de descanso.

Esto último tendría que lograrse mediante la aplicación de los procedimientos y dispositivos antes indicados. En cuanto a los procedimientos, básicamente deberían apuntar a reglamentar el uso de las comunicaciones digitales con el objeto que éstas no se envíen fuera de los horarios de trabajo, salvo en casos excepcionales, como pueden ser ciertos cargos (según lo contempla el proyecto), o supuestos de caso fortuito o fuerza mayor. En cuanto a los dispositivos, en buena medida, deberían referirse a mecanismos informáticos que permitan impedir que mensajes enviados fuera de la jornada puedan llegar a su receptor.

En relación a la ocurrencia de un caso fortuito o fuerza mayor, nos parece que sería necesario contemplar esta posibilidad como una hipótesis donde sería posible dejar sin efecto el derecho a la desconexión, tal como se pactaba en algunos convenios colectivos en España, según veíamos. A este respecto, resulta un buen parámetro, el art. 29 CdT que contempla la posibilidad de exceder la jornada ordinaria de trabajo, “(...) en la medida indispensable para evitar perjuicios en la marcha normal del establecimiento o faena, cuando sobrevenga fuerza mayor o caso fortuito, o cuando deban impedirse accidentes o efectuar arreglos o reparaciones impostergables en la maquinarias o instalaciones". En este caso, "las horas trabajadas en exceso se pagarán como extraordinarias" (cfr. inc. 2 art. 29 CdT). Para el caso de la desconexión, pensamos que, si ésta se tiene romper por este motivo, sería necesario que el trabajador reciba un beneficio remuneratorio por ello, tal como lo exige este proyecto de ley para los casos exceptuados (según lo explicamos en el apartado 5.4). Así, por ejemplo, la Dirección del Trabajo ha considerado que constituyó fuerza mayor la suspensión del tránsito marítimo decretada por el Gobernador Marítimo de Aysén, y facultó a las empresas salmoneras para prolongar la jornada de trabajo bisemanal de los trabajadores que permanecieron en el lugar de faena a raíz de esta emergencia ${ }^{43}$.

\subsection{Sobre quién envía la comunicación}

Sobre este aspecto, el proyecto de ley establece que las comunicaciones que el trabajador no está obligado a responder son aquellas que provengan de "sus empleadores o jefaturas, proveedores, clientes o consumidores con que se relacione la empresa o establecimiento, obra o faena, cualquiera sea el medio a través del cual éstas se realicen". Es posible advertir, que los emisores pueden ser, bien, personas de la propia empresa -empleadores o jefaturas-, bien, personas que se relacionan con ella -proveedores, clientes o consumidores -.

Con respecto a quienes son parte de la empresa, se hace sólo mención al empleador o trabajadores que tengan cargos superiores con relación a los destinatarios del mensaje. Es decir, el proyecto de ley considera que dichas personas, en exclusiva, pueden afectar el derecho a la desconexión. De modo, que la alteración o interrupción del descanso se daría en clave vertical descendente en relación al organigrama empresarial ${ }^{44}$.

43 Dictamen N 3592/266, 18.05.2004, cit. en Eduardo Caamaño Rojo, Código del Trabajo, Santiago de Chile, Thomson Reuters, 2016, t. I, 486-487. El Dictamen señalado indica que “...la resolución del Gobernador Marítimo originó en los hechos un doble impedimento, por una parte, la imposibilidad de unos trabajadores de regresar al puerto para su descanso, como de los otros para llegar al lugar de las faenas y, por otra, la absoluta imposibilidad de la empresa para reemplazar al único personal que terminada su jornada bisemanal, considerando que la situación de fuerza mayor analizada, además, ocurre en lugares apartados y en condiciones climáticas inestables y riesgosas (...).

44 Tomamos las expresiones "vertical" y "horizontal" que son usada para referirse a supuestos de acoso o mobbing vértical descendente (de cargos superiores a trabajadores que están bajo su dirección), ascendente (de trabajadores a cargos superiores), y horizontal (entre trabajadores de la misma jerarquía); véase Francisco Javier Abajo Olivares, Mobbing. Acoso psicológico en el ámbito laboral, Buenos Aires, Abeledo Perrot, 2010, 19ss. Utilizando las expresiones "acoso vertical” y "acoso horizontal”, véase José Luis Ugarte Cataldo, Derechos fundamentales. Tutelay Trabajo, Santiago de Chile Thomson Reuters, 2018, 130. 
No compartimos este punto de la propuesta legislativa, ya que la vulneración del descanso -vía comunicaciones- se puede llevar a cabo entre trabajadores pares -esto es, horizontal-, como también de trabajadores respecto de sus superiores jerárquicos -esto es, vertical ascendente-. Asimismo, incluso al hablarse únicamente de "jefaturas", podría resultar sencillo burlar la norma, pues se podría sostener que quienes envían las comunicaciones fuera de jornada no tienen nominalmente la categoría de jefe de área -o cualquier denominación semejante- en el organigrama de funciones de la empresa.

Por consiguiente, creemos que hubiera sido de mayor conveniencia no aludir sólo a "jefaturas", sino, más bien, a trabajadores -además del empleador-. Y es que nos parece una visión restrictiva estimar que la vulneración de la desconexión puede provenir puramente desde cargos superiores. El problema de la hiperconexión digital es transversal, y una comunicación de un trabajador a un superior -que igualmente es un trabajador- fuera de su jornada, puede igualmente alterar su derecho a descanso. Asimismo, como antes apuntábamos, si los emisores de mensajes son trabajadores de la empresa sería recomendable reglamentar el uso de los correo o mensajes de trabajo con el objetivo que no se afecten el derecho de la desconexión. Es decir, sería necesario establecer la prohibición de enviar comunicaciones relativas a la empresa fuera del horario de trabajo.

Veíamos que el trabajador tampoco tiene la obligación de contestar la comunicación de personas que se relacionan con la empresa, como es el caso de proveedores, clientes o consumidores. Es evidente que la reglamentación indicada en el párrafo anterior no puede aplicarse para estas personas dado que no son parte de la empresa. De modo que no se les puede impedir que envíen comunicaciones fuera de las jornadas de trabajos de sus receptores, que, por lo demás, es una cuestión que no tiene por qué tener conocimiento. Con todo, hacíamos referencia a que la empresa puede implementar dispositivos informáticos con miras a que dichas comunicaciones lleguen a sus trabajadores sólo durante sus respectivas jornadas.

\subsection{Supuestos exceptuados de la desconexión}

El proyecto contempla un caso de excepción de la desconexión. Se trata de ciertos trabajadores que podrían recibir comunicaciones fuera de su horario de trabajo. Estos son aquellos trabajadores que pueden ser excluidos de negociar colectivamente (cfr. art. 305 CdT). Por una parte, se encuentran "los trabajadores que tengan facultades de representación del empleador y que estén dotados de facultades generales de administración, tales como gerentes y subgerentes"; por otra, el "personal de confianza que ejerza cargos superiores de mando" en la micro o pequeña empresa.

En el primer supuesto, más allá de las denominaciones que pueda llegar a recibir (p. ej. gerente, subgerente, agente o apoderado), se exige que cuente "a lo menos, de facultades generales de administración". Como se aprecia, se trata de una condición bastante exigente dada la clase de apoderamiento requerida. Esta excepción se explica por la condición de alter ego del empleador de esta clase de cargos, toda vez que es un mandatario del empresario — sea individual o social — en sentido mercantil, y como delegado de éste — su alter ego — hace las veces de controlador laboral pues dirige las labores de los trabajadores ${ }^{45}$. Un razonamiento similar podría aplicarse sobre el personal de confianza de la micro y pequeña empresa que ejerza cargos superiores de mando. Ello debido a que, en estas empresas por su tamaño, suele suceder que las personas encargadas de labores de dirección realizan dichas funciones por encargo del empleador, pero sin contar con poderes formales. Por tal motivo, aun sin contar con dicho mandato escrito, pero si ejercen la dirección y la administración de la empresa de manera habitual se entiende que representan al empleador (cfr. inc. $1^{\circ}$ art. $\left.4 \mathrm{CdT}\right)^{46}$. El mensaje del proyecto de

45 Véase sobre la condición de alter ego de estos cargos respecto del empleador, véase Gonzalo Diéguez Cuervo, "La quiebra del concepto de ajeneidad en la Seguridad Social y su significado", José Luis Monereo et al (coords.), La Seguridad Social a luz de sus reformas pasadas, presentes y futuras: Homenaje al profesor José Vida Soria con motivo de su jubilación, Granada, Comares, 2008, $364-365$. 46 Alfredo Sierra Herrero, “Aspectos laborales del gerente: representación empresarial y desahucio”, Revista de Derecho de la Empresa (Universidad Adolfo Ibáñez), N²0, 2009, 14. 
ley no explica la razón de por qué esta clase de trabajadores estarían excluidos de la desconexión laboral. La misma seguramente se encuentra en la cercanía de éstos con el empleador, pues, en buena medida, sus funciones consisten en las tareas delegas que son propios de aquel. Es decir, la "dirección y organización del trabajo ajeno que contrata”, incluyendo desde luego la facultad de despedir ${ }^{47}$.

Con todo, la excepción a la desconexión no es absoluta, más bien, es bastante restringida. Para que opere este régimen es necesario "acordar, de manera excepcional", esta posibilidad con el trabajador, y siempre que se cumplan una serie de condiciones, a saber: a) se pueden enviar comunicaciones que estén descritas detalladamente en el respectivo contrato; b) tiene que implicar beneficios específicos para los trabajadores; c) no puede constituir una renuncia absoluta al derecho o que lo limiten de manera irracional o desproporcionada. A continuación, veremos cada una de estas exigencias

a) Se requiere que estas comunicaciones estén detalladas específicamente en el contrato. Si no se plasma esta estipulación, el trabajador se encontraría en el régimen general, y, por tanto, su derecho a desconexión no podría afectarse por las comunicaciones que reciba en su descanso. Cabe destacar que se permite este acuerdo, pero siempre que sea con carácter "excepcional". Consideramos que esta exigencia ha de implicar que este detalle de comunicaciones deber ser en términos concretos, ya que si se establecen en términos generales quedaría prácticamente sin efecto el carácter especial de esta posibilidad de conexión con dichos cargos.

b) Sobre los beneficios específicos, en los términos planteados significaría que por la circunstancia de que se pacte esta posibilidad en el contrato, el trabajador tendría que recibir algún tipo de contrapartida. No se específica en qué puede consistir estos beneficios, pero cuando se utiliza esa denominación, suele asociarse con contraprestaciones remuneratorias. Pensamos que en la práctica tal exigencia se materializaría mediante la incorporación de una nueva partida salarial. Esta partida normalmente tendría el carácter mensual y sería de carácter fija, sin importar el número de conexiones fuera de jornada. El problema de esta posibilidad es que bajo la denominación de, por ejemplo, "bono o incentivo por conexión durante el descanso", se podría disfrazar lo que en verdad es un sueldo ${ }^{48}$. De esta suerte, si dicha partida es lo que se podría decir un sueldo simulado, no estaría retribuyendo, en el fondo, la vuelta a conectarse en el trabajo, sino, más bien, la prestación ordinaria de servicios.

Por estas razones, parece más aconsejable que si se pretende establecer un incentivo para el trabajador -pero que sea también un mayor costo para la empresa-, se apunte al devengamiento del mismo en cada oportunidad que se altere o interrumpa el descanso, con motivo de las comunicaciones provenientes de su empresa. Es decir, debería seguirse un esquema similar a lo que sucede con el régimen de horas extraordinarias. Este encarecimiento para la empresa, ayudaría, sin dudas, a lo indicado en la letra c), en orden a que la limitación del derecho a la desconexión sea proporcionada.

c) Finalmente se exige que este régimen de excepción no implique "una renuncia absoluta al derecho o que lo limiten de manera irracional o desproporcionada". Esta condición se lograría, en buena medida, si se cumplen las dos anteriores. Esto debido a que, si las comunicaciones tienen que ser específicamente detalladas en el contrato, e importa el otorgamiento de un beneficio cada vez que se genere el aviso, se impediría que se limite el derecho a la desconexión de forma irracional o desproporcionada.

Con todo, consideramos que sería recomendable no hablar de "renuncia absoluta", pues se podría interpretar, en forma errónea, que este derecho podría restringirse más allá de su núcleo esencial, siempre que queden algunos atisbos del mismo. En efecto, si se establece como límite el respecto a la esencia del derecho, implicaría que no podría ser privado de aquello que le es consustancial, de manera tal que deje de ser reconocible (nota). Son, por lo demás, los términos que se utilizan a propósito de la tutela laboral.

\footnotetext{
47 Véase Diéguez Cuervo, op. cit., 364-365.

48 Sobre la utilización de un verdadero sueldo bajo otras denominaciones, véase Alfredo Sierra Herrero, "Los bonos y participaciones como componentes del régimen retributivo de los trabajadores", Revista Internacional y Comparada de Relaciones Laborales y Derecho del Empleo, vol. 4, N 3, 2016, 6.
} 
El inc. 2 art. 485 CdT, relativo a la tutela laboral, es un buen parámetro a este respecto. En efecto, su tenor permite -entendido a contrario sensu- que el empleador pueda limitar un derecho fundamental de un trabajador, siempre y cuando tenga "justificación suficiente", que no sea "en forma arbitraria o desproporcionada", o se respete su "contenido esencial". A su vez, nos parece relevante subrayar que el artículo citado requiere una "justificación suficiente" para limitar el derecho fundamental. Esta justificación tendrá que fundamentarse normalmente en la protección de un derecho fundamental (pero) del empleador $-\mathrm{O}$ el resto de los trabajadores- que podría verse seriamente afectado, si no se limita proporcionalmente un derecho fundamental de un trabajador ${ }^{49}$.

Pensamos que, si bien en el proyecto de desconexión laboral no se requiere esta "justificación suficiente" (dentro de la excepción comentada), en buena parte, ella sí estaría cubierta por la exigencia de que estas comunicaciones estén detalladas específicamente en el contrato (según indicábamos en la letra a). $\mathrm{Y}$ es que, como indicamos, dado que el detalle de comunicaciones debe hacerse en términos concretos, tal necesidad va significar que dicha descripción conlleve que los supuestos descritos impliquen, en el fondo, una "justificación suficiente" de la limitación al derecho de desconexión.

\section{Consideraciones finales}

El impacto de las nuevas tecnologías en el mercado laboral a través de la implementación de herramientas digitales de forma generalizada (teléfonos inteligentes, ordenadores portátiles, tabletas) ha dado lugar a un mayor desarrollo de nuevas formas de trabajo más flexibles que facilitan la conciliación de la vida laboral y familiar como es el caso del teletrabajo o el trabajo a distancia, etc.

No obstante, han provocado también un efecto negativo consistente en un reforzamiento de la vinculación de los trabajadores al trabajo, en especial, fuera del horario laboral. Aunque es cierto que la normativa legal reguladora del tiempo de trabajo y de los descansos protege el derecho a no contestar emails o llamadas telefónicas una vez finalizada la jornada laboral, ya que supone un incumplimiento del período de descanso (extensible al derecho a la conciliación de la vida personal, familiar y laboral de los trabajadores), la realidad es que es una práctica, extendida en muchas empresas, frente a la que un trabajador no puede negarse en la mayoría de los casos.

De ahí que se imponga la necesidad de reforzar y/o adecuar el marco normativo laboral a esta nueva realidad, ya sea a través del reconocimiento del derecho a la desconexión laboral o a través de una reforma de la regulación del tiempo de trabajo, en la que se contemple la necesidad de respetar los descansos, prohibiendo el envío de e-mails o la realización de llamadas telefónicas fuera de la jornada laboral, y contemplando el derecho a no contestar esas comunicaciones en tales períodos.

Es por ello que el reconocimiento del derecho a la desconexión laboral o el reforzamiento del derecho al descanso es, ante todo, un mensaje importante hacia los trabajadores, mensaje de compromiso a favor de una política efectiva de respeto del tiempo de descanso y favorecedora de una conciliación efectiva de la vida laboral y la vida privada de ellos.

En síntesis, es necesario aprovechar la potencialidad del uso de las nuevas tecnologías en el marco del trabajo que son y serán, sin duda alguna, un elemento fundamental en el marco del futuro del trabajo, pero es necesario evitar que éstas se conviertan en un instrumento de abuso en el uso del tiempo de trabajo excediendo los límites de duración de la jornada. La regulación convencional y/o normativa de la desconexión laboral es un claro llamamiento al respeto del derecho al descanso diario, semanal y anual de los trabajadores para evitar que la conectividad permanente menoscabe estos derechos y amplíe, sin

49 Sobre la justificación y la proporcionalidad de la limitación de un derecho fundamental de un trabajador, véase Corte de Apelaciones de Santiago 9 febrero de 2018, Rol 2134-2017. Sobre la posibilidad de limitar legítimamente un derecho fundamental, véase Ugarte Cataldo, op. cit., 235ss. 
límites o con límites más difusos, el poder empresarial de especificación de la prestación de trabajo durante los tiempos de no trabajo.

\section{Bibliografía}

Francisco Javier Abajo Olivares, Mobbing. Acoso psicológico en el ámbito laboral, Buenos Aires, AbeledoPerrot, 2010.

Raquel Aguilera y Rosario Cristóbal, "Nuevas tecnologías y tiempo de trabajo: el derecho a la desconexión tecnológica", El futuro del trabajo que queremos. Conferencia Nacional Tripartita, 28 de marzo de 2017, Iniciativa del Centenario de la OIT (1919-2019), 2017, vol. 2, 331-342.

Héctor Hugo Barbagelata, Curso sobre la evolución del pensamiento juslaboralista, Montevideo, Fundación de Cultura Universitaria, 2011, 46.

Jaime Cabeza Pereiro, "Las fuentes reguladoras de la jornada de trabajo", Joaquín Aparicio y Juan López (coords.), Tiempo de trabajo, Albacete, Bomarzo, 2007, 13-32.

Eduardo Caamaño Rojo, Código del Trabajo, Santiago de Chile, Thomson Reuters, 2016, t. I.

María Belén Cardona Rubert, "Las Relaciones Laborales y el uso de las tecnologías Informáticas", Lan barremanak: Revista de relaciones laborales, Núm. Extraordinario 1, 2003, 157-173, 157.

Alejandro Castello, “Jornada de trabajo”, Juan Razo (dir.), Derecho del Trabajo, t. II, 7-28, 8.

Miguel Ángel Chamocho Cantudo, Introducción jurídica a la historia de las relaciones de trabajo, Madrid, Dykinson, 2013, 167.

Gonzalo Diéguez Cuervo, "La quiebra del concepto de ajeneidad en la Seguridad Social y su significado", José Luis Monereo et al (coords.), La Seguridad Social a luz de sus reformas pasadas, presentes y futuras: Homenaje al profesor José Vida Soria con motivo de su jubilación, Granada, Comares, 2008.

Óscar Ermida Uriarte, Meditación sobre el Derecho del Trabajo, Montevideo, Fundación Electra, 2011, 9.

Sergio Gamonal y Caterina Guidi, Manual del contrato de trabajo, Santiago de Chile, Thomson Reuters, 2015, 197.

Ignacio García-Perrote Escartín, Manual de Derecho del Derecho, Valencia, Tirant Lo Blanch, 2012, 433.

Luis Lizama y Diego Lizama, Manual de Derecho individual de Trabajo, Santiago, Ediciones DER.

Antonio Martín, Fermín Rodríguez-Sañudo y Joaquín García, Derecho del Trabajo, Madrid, Tecnos, 2016, 543.

Nora María Martínez Yáñez, El régimen jurídico de la disponibilidad horaria, Pamplona, Thomson Reuters, 2011. 
Cristóbal Molina Navarrete, "Jornada laboral y tecnologías de la infocomunicación: 'desconexión digital', garantía del derecho al descanso", Temas laborales: Revista andaluza de trabajo y bienestar social, No 138, 2017, 249-283.

Laëtitia Morel, "Le droit à la déconnexion en droit français : la question de l'effectivité du droit au repos à l'ère du numérique”, Labor \& Law Issues, vol. 3, N² 2, 2017, 1-16.

Miguel A. Pirolo, “Jornada de trabajo”, Jorge Rodríguez (dir.), Derecho del Trabajo, Buenos Aires, Editorial Astrea, 2010, 547-589, 549.

María Luz Rodríguez Fernández, "Plataformas, microworkersy otros retos del trabajo en la era digital", Oficina de la Organización Internacional del Trabajo para España, Futuro del Trabajo. Trabajo decente para todos, 2017, 10 (disponible en línea: https://www.ilo.org/madrid/fow/trabajo-decente-paratodos/WCMS 548596/lang--es/index.htm).

Irene Rojas Miño, Derecho del Trabajo. Derecho individual del trabajo, Santiago de Chile, Thomson Reuters, $2015,181$.

Alfredo Sierra Herrero, "Los bonos y participaciones como componentes del régimen retributivo de los trabajadores", Revista Internacionaly Comparada de Relaciones Laborales y Derecho del Empleo, vol. 4, N 3, 2016, $2-13$.

Alfredo Sierra Herrero, “Aspectos laborales del gerente: representación empresarial y desahucio", Revista de Derecho de la Empresa (Universidad Adolfo Ibáñez), N² 20, 2009, 9-38.

José Luis Ugarte Cataldo, Derechos fundamentales. Tutela y Trabajo, Santiago de Chile Thomson Reuters, 2018. 